\title{
Biosimilars: concept, current status, and future perspectives in inflammatory bowel diseases
}

\author{
Sang Hyoung Park ${ }^{1 *}$, Jae Cheol Park ${ }^{1 *}$, Milan Lukas², Martin Kolar², Edward V. Loftus, Jr. ${ }^{3}$ \\ ${ }^{I}$ Department of Gastroenterology, Asan Medical Center, University of Ulsan College of Medicine, Seoul, Korea; ${ }^{2}$ IBD Clinical and Research \\ Centre, ISCARE Lighthouse and First Faculty of Medicine, Charles University, Prague, Czech Republic; ${ }^{3}$ Division of Gastroenterology and \\ Hepatology, Mayo Clinic, Rochester, MN, USA
}

The inflammatory bowel diseases (IBD), which consist of Crohn's disease and ulcerative colitis, are chronic, incurable immunemediated inflammatory disorders of the intestine. As IBD incidence continues to increase globally and its mortality is low, prevalent cases of IBD are rapidly increasing, thereby leading to a substantial increase in health care costs. Although the introduction of biologic agents for IBD management has revolutionized the armamentarium of IBD therapy, the high cost of this therapy is concerning. With the expirations of patents for existing biologic agents (originals), biosimilars with cheaper costs have been highlighted in the field of IBD. Despite concerns regarding their short- and long-term efficacy, safety, immunogenicity, and interchangeability, increasing evidence via prospective observations and phase III or IV clinical trials, which aim to prove the "biosimilarity" of biosimilars to originals, has partly confirmed their efficacy, safety, and interchangeability. Additionally, although patients and physicians are reluctant to use biosimilars, a positive budget impact has been reported owing to their use in different countries. In the near future, multiple biosimilars with lower costs, and efficacy and safety profile similar to originals, could be used to treat IBD; thus, further consideration and knowledge dissemination are warranted in this new era of biosimilars. (Intest Res 2020;18:34-44)

Key Words: Biosimilars; Inflammatory bowel diseases; Crohn disease; Colitis, ulcerative; Biologic factors

\section{INTRODUCTION}

Crohn's disease (CD) and UC are 2 major subtypes of IBD that may cause chronic inflammation throughout the intestine, thereby resulting in hospitalization and surgery, which impair the quality of life of patients. IBD is an incurable immune-mediated chronic disorder with low mortality that requires lifelong

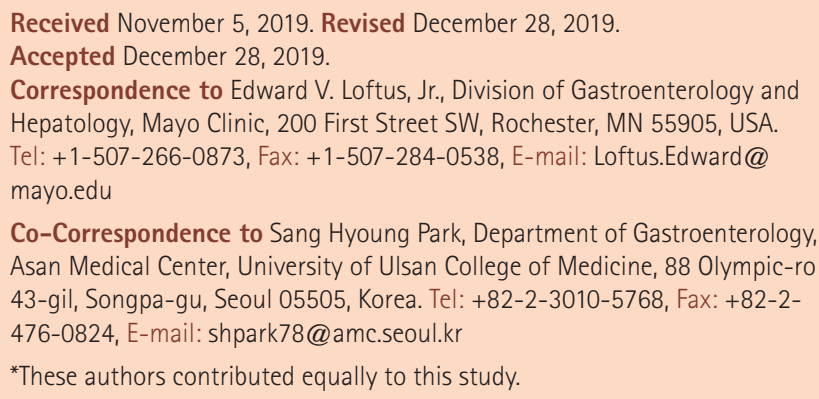

management with anti-inflammatory agents, immunosuppressants, and biologic agents. In particular, the development and introduction of biologic agents with high efficacy and a good safety profile to IBD therapy have dramatically changed the treatment strategy of IBD therapy. In addition, the use of biologic therapy for the treatment of IBD has continuously increased during past decades in Western and Eastern countries. $^{1-3}$

The incidence of IBD continues to increase globally, including North America, the United Kingdom, Northern Europe, Australia, and recently developing regions such as Asia, the Middle East, and South America. ${ }^{4}$ Currently, the prevalence of IBD in Western countries is up to $0.5 \%$ of the general population. ${ }^{5}$ Because the incidence and prevalence of IBD continues to increase, the direct and indirect costs of IBD in Western countries are subsequently increasing. In the United States, 
direct medical costs related to IBD were more than USD 6 billion in 2004. ${ }^{6,7}$ The major health care costs in IBD management are driven by hospitalizations, surgery, outpatient visits, procedures, and pharmaceuticals. More importantly, the increasing use of biologic agents has led to a considerable rise in health care cost for IBD patients. ${ }^{8}$ Currently, the patents of several biologic agents have either expired or are close to expiration, enabling the entry of copy versions of the original biologic agents, called biosimilars, into the market. ${ }^{9}$ The introduction of biosimilars is expected to reduce health care costs and increase treatment access for patients with chronic, incurable immune-mediated disorders, such as IBD. ${ }^{10}$ Because of the brief history of biosimilars, there are several debates regarding its biosimilarity, such as its efficacy, safety, immunogenicity, interchangeability, etc. to their originals. Therefore, in this review, we aimed to discuss the concept and the current status of biosimilars, and the future perspectives of biosimilars in the field of IBD on the global scale.

\section{THE CONCEPT OF BIOSIMILAR}

Although biosimilars are known as highly similar agents to the originals (the reference biologic products), they should not be referred to as, nor equated with, generic drugs, which are equivalent to original products in several aspects such as dosage, strength, route of administration, performance, etc. There should be no clinically meaningful differences between biosimilars and their originals based on safety, purity, or potency. ${ }^{11}$ Because biologic agents are synthesized in living cells, 2 biologic drugs cannot be structurally identical due to unique posttranslational modifications. Of note, the scientific principles underlying comparability that are applicable to biosimilars are the same as those related to changes in the manufacturing process of the originals. For example, since the first approval of infliximab (Remicade ${ }^{\circledR}$; Janssen Biotech, Inc, Horsham, PA, USA) in 1999, there have been more than 35 changes in the manufacturing process for its production, including process improvements, scale changes, and site transfers. However, acceptable product quality and comparability have always been demonstrated during these changes. ${ }^{12,13}$

\section{REGULATORY PATHWAY FOR BIOSIMILARS}

The regulatory process for the approval of biosimilars differs from that of original drug products. ${ }^{14,15}$ For new biologic agents (i.e., originals), they must be tested in each clinical indication for which approval is sought; this step is usually the most timeconsuming and costly phase of new biologic development. In contrast, for biosimilars, an abbreviated approval process can be used, which mainly focuses on its structural, analytical, and in vitro similarity to the reference product. Following this pathway, only one comparative clinical trial that includes assessment of pharmacokinetics and immunogenicity is required before the approval of biosimilars and these data can be extrapolated to other indications. Through this pathway, the first biosimilar to infliximab, CT-P13 (Remsima; Celltrion, Incheon, Korea and infliximab-dyyb, Inflectra ${ }^{\circledR}$; Pfizer, New York, NY, USA), was approved by the European Medicines Agency (EMA) in 2013 and the US Food and Drug Administration (FDA) in April 2016. ${ }^{16,17}$ The use of CT-P13 for IBD indications was extrapolated from the results of randomized clinical trials (RCTs) in rheumatoid arthritis (RA) and ankylosing spondylitis (AS) ${ }^{18,19}$ To date, a growing body of evidence from several retrospective and pharmacovigilance data continue to support the proposal that the efficacy and safety of CT-P13 is comparable to those of the original drug. ${ }^{20-22}$

\section{EFFICACY AND SAFETY IN PROSPECTIVE STUDIES}

The first prospective, observational study assessing the efficacy, tolerability, and safety of CT-P13 was presented by Jahnsen et al. in $2015 .{ }^{23}$ From January 2014 to February 2015, a total of 78 IBD patients (46 with CD and 32 with UC) were recruited, and $30 \%$ of $\mathrm{CD}$ and $25 \%$ of UC patients were previously treated with anti-TNF agents. In CD, 79\% of patients (34/43) achieved clinical remission, which was defined as a Harvey-Bradshaw index score $\leq 4$ at week 14 . In UC patients, the remission rate, defined by the partial Mayo score $\leq 2$, was $56 \%(18 / 32)$ at week 14 . During the study period, there were no unexpected adverse events. In 2017, Gecse et al. ${ }^{24}$ reported the final results from a prospective, multicenter, nationwide Hungarian IBD cohort, including 353 consecutive patients receiving CT-P13 (209 with CD and 144 with UC), of whom 229 patients reached the 54-week endpoints. In patients with $\mathrm{CD}$, clinical remission was achieved in $49 \%, 53 \%$, and $48 \%$ of patients, while clinical response was observed in $86 \%, 81 \%$, and $65 \%$ of patients, at weeks 14,30 , and 54, respectively. In UC, clinical remission was detected in $56 \%, 41 \%$, and $43 \%$ of patients, while clinical response was observed in $74 \%, 66 \%$, and $50 \%$ of patients, at weeks 14, 30, and 54, respectively. Patients who had previously received anti-TNF therapy showed significantly lower remission and response rates at weeks 14, 30, and 54 for 
both CD and UC. Infusion reactions were reported in $8.8 \%$ of patients, while infections were reported in $9 \%$ of patients; 1 death was also observed. There were no new safety signals from this cohort of patients. Recently, the largest experience with CT-P13 was demonstrated via an Italian prospective, nationwide, multicenter, observational cohort, named PROSIT, which evaluated its safety, and its clinical and endoscopic efficacy. ${ }^{25}$ These researchers recruited 680 consecutive IBD patients ( 373 with CD and 307 with UC) from 25 sites and mean follow-up was 32 weeks. This heterogeneous cohort of patients comprised 400 patients naive to anti-TNF therapy, 171 patients who were previously exposed to biologic agents, and 109 patients who were switched from originator infliximab to CT-P13. Although primary failure of induction therapy was observed in $8.1 \%$ of patients, as a whole, $45.6 \%(274 / 601)$ of patients were in remission, 30.9\% (186/601) were deemed responders, and 10.3\% (62/601) experienced loss of response during the follow-up without new safety signals. Additionally, deep remission was achieved in $57 \%$ of $\mathrm{CD}$ and $50 \%$ of UC patients (Table 1).

The efficacy of CT-P13 induction therapy on mucosal healing in patients with UC was evaluated by Farkas et al. ${ }^{26}$ in a prospective, multicenter Hungarian and Czech study. Altogether, 63 consecutive UC patients receiving CT-P13 therapy due to acute, severe relapse (24 patients) or for chronic refractory disease activity (39 patients) were included. Cumulative clinical response and steroid-free remission at week 14 were achieved in $82.5 \%$ and $47.4 \%$ of patients, respectively. Mucosal healing, which was defined as an endoscopic Mayo score of 0 or 1 , was detected in $47.6 \%$ of patients, and complete mucosal healing (i.e., endoscopic Mayo score 0) was found in $27 \%$ of patients. RCTs of the originator infliximab resulted in clinical response, remission, and mucosal healing rates of $69 \%, 39 \%$, and $62 \%$, respectively, at week 8 in Active Colitis Trials (ACT) 1 and $65 \%, 34 \%$, and $60 \%$ at week 8 in ACT $2 .^{27}$ Compared to the ACT 1 and 2 results, the higher response and remission rate and the comparable rate of mucosal healing in this study could be explained by the longer term of outcome evaluations in this study (week 14 vs. week 8), and may support the notion that real-life data depict better outcomes than clinical trials.

Recently, Ye et al. ${ }^{28}$ reported the results from a phase III randomized, double blind parallel group trial, conducted in patients with moderate to severe CD. These authors compared the efficacy of CT-P13 to originator infliximab, with 220 patients from 16 countries. The primary outcome of this study was to compare the efficacy between 2 groups based on CDAI-70 response rates (defined as a reduction from the baseline CDAI score by at least 70 points) at week 6 . In a per protocol analysis, CDAI-70 response rate was quite similar (CT-P13 69.4\% vs. originator 74.3\%: difference, 4.9\%; 95\% CI, 16.9-7.3) and based on the significant clinical response

Table 1. Prospective Studies for the Clinical Efficacy of CT-P13 in IBD

\begin{tabular}{|c|c|c|c|c|c|}
\hline Study & Country & Design & $\begin{array}{l}\text { Sample } \\
\text { size }\end{array}$ & $\begin{array}{l}\text { Follow-up } \\
\text { (wk) }\end{array}$ & Outcome \\
\hline Jahnsen et al. ${ }^{23}$ & Norway & Observational & $\begin{array}{l}\text { Total } 78, \text { CD } 46 \\
\text { UC } 32\end{array}$ & 14 & $\begin{array}{l}\text { Clinical remission in CD: } 79 \% \text { at wk } 14 \\
\text { Clinical remission in UC: 56\% at wk } 14\end{array}$ \\
\hline Gecse et al. ${ }^{24}$ & Hungary & Observational & $\begin{array}{l}\text { Total } 353, \text { CD } \\
\text { 209, UC } 144\end{array}$ & $54^{\mathrm{a}}$ & $\begin{array}{l}\text { Clinical response in CD: } 86 \%, 81 \% \text {, and } 65 \% \text { at wk 14, 30, and } 54 \\
\text { Clinical remission in CD: 49\%, 53\%, and 48\% at wk 14, 30, and } 54 \\
\text { Clinical response in UC: } 74 \%, 66 \% \text {, and } 50 \% \text { at wk 14, 30, and } 54 \\
\text { Clinical remission in UC: } 56 \%, 41 \% \text {, and } 43 \% \text { at wk 14, 30, and } 54\end{array}$ \\
\hline Guidi et al. ${ }^{25}$ & Italy & Observational & $\begin{array}{l}\text { Total 680, CD } \\
373, \text { UC } 307\end{array}$ & 32 & $\begin{array}{l}\text { Clinical remission: } 45.6 \% \text {, clinical response: } 30.9 \% \text {, loss of } \\
\text { response: } 10.3 \% \\
\text { Deep remission in CD 57\% } \\
\text { Deep remission in UC 50\% }\end{array}$ \\
\hline Farkas et al. $^{26}$ & $\begin{array}{l}\text { Hungary, } \\
\text { Czech }\end{array}$ & Observational & UC 63 & 14 & $\begin{array}{l}\text { Clinical response: } 82.5 \% \\
\text { Mucosal healing: } 47.6 \%\end{array}$ \\
\hline Ye et al. ${ }^{28}$ & 16 Countries & $\begin{array}{l}\text { Phase III, } \\
\text { randomized, } \\
\text { double blind, } \\
\text { parallel group }\end{array}$ & CD 220 & 30 & $\begin{array}{l}\text { Clinical response (CDAI-70) at wk 6: CT-P13 69.4\% vs. IFX 74.3\% } \\
\text { (difference, 4.9\%; 95\% Cl, 16.9-7.3) } \\
\text { Clinical response (CDAI-70) at wk 30: CT-P13 76.6\% vs. IFX 75.2\% } \\
\text { (difference, } 1.3 \% ; 95 \% \mathrm{Cl}, 10.3-12.9 \text { ) }\end{array}$ \\
\hline
\end{tabular}

a229 Patients reached the 54-week endpoint.

IFX, originator infliximab. 
(CDAI-100 response, decrease in CDAI score of at least 100 points from baseline), no difference was observed (CT-P13 $60.4 \%$ vs. originator $64.2 \%$ : difference, $3.9 \%$; $95 \%$ CI, 16.7-9.6). Week 30 data also revealed similar results between the 2 groups based on CDAI-70 response rate, CT-P13 76.6\% versus originator 75.2\%; CDAI-100 response rate, CT-P13 72.1\% versus originator 73.4\%; and clinical remission (CDAI score of less than 150 points) rate, CT-P13 55.0\% versus originator $56.9 \%$. In this randomized study, CT-P13 was well tolerated and displayed a safety profile comparable to that of originator up to 30 weeks. The result of this phase III study may help overcome the concern regarding the extrapolation issue related to biosimilars.

\section{SWITCH FROM THE ORIGINAL TO THE BIOSIMI- LAR, INFLIXIMAB}

The NOR-SWITCH Study was a 52-week, randomized, noninferiority double blind trial that examined switching from reference infliximab to CT-P13 and its efficacy, safety, and immunogenicity. ${ }^{29}$ This study was financed by the Norwegian Government and monitored using the health care system. Adult patients on stable treatment with reference infliximab and treated in the hospital settings for at least 6 months were recruited to participate in this study. The primary endpoint was disease worsening during a 52-week follow-up period. Overall, 482 patients across multiple indications were enrolled and randomized in a 1:1 ratio (241 to reference infliximab and 241 to CT-P13). Patients suffered from CD (32\%, 155 patients), UC (19\%, 93 patients), and the remaining 233 patients (49\%) suffered from other diseases, including AS (19\%), RA (16\%), psoriatic arthritis (6\%), and chronic plaque psoriasis (7\%). Across all indication, disease worsening was detected in $26 \%$
(53 patients) on originator infliximab and 30\% (61 patients) of patients in the CT-P13 group (adjusted treatment difference, $4.4 \%$; 95\% CI, 12.7-3.9). The frequency of serious adverse events was $10 \%$ in the reference group and 9\% in the CT-P13 group, and the same frequency of adverse events led to therapy discontinuation ( $4 \%$ vs. $3 \%$, respectively). The authors concluded that switching from originator infliximab to CT-P13 was not inferior to continued treatment with originator, according to a pre-specified non-inferiority margin of $15 \%$. Although this study was not powered to demonstrate non-inferiority in individual diseases, authors performed an explorative subgroup analysis in 129 CD patients and 75 UC patients, and the result showed similarity between patients treated with originator infliximab and CT-P13 based on efficacy, safety, and immunogenicity (Table 2). ${ }^{30}$

Another experience of switching was summarized by Kolar et al. ${ }^{31}$ from one tertiary site in the Czech Republic. In this study, there were 2 cohorts of patients: cohort 1, 74 IBD patients (56 with CD and 18 with UC) who were switched from originator infliximab to CT-P13; and cohort 2, 119 infliximab-naive patients (90 with CD and 29 with UC) who were newly administered CT-P13. In the switching cohort, most patients remained stable, and the remission rate at weeks 0 and 56 were $72.2 \%$ versus $77.8 \%$, respectively. The median difference between both Harvey-Bradshaw index scores in CD and Simple Clinical Colitis Activity Index scores in UC between weeks 0 and 56 was 0 . Additionally, there were no significant differences in CRP $(4.3 \pm 8.0 \mathrm{mg} / \mathrm{L}$ vs. $3.3 \pm 3.8 \mathrm{mg} / \mathrm{L} ; P=0.82)$ or fecal calprotectin $(135 \pm 153 \mu \mathrm{g} / \mathrm{g}$ vs. $199 \pm 225 \mu \mathrm{g} / \mathrm{g} ; P=0.84)$. In the infliximab-naive cohort, $92 \%$ and $86 \%$ of CD patients and $83 \%$ and $64 \%$ of UC patients responded to CT-P13 at weeks 14 and 46, respectively. Moreover, half of the UC patients experienced mucosal healing at week 14 , and $95 \%$ of CD patients experi-

Table 2. Prospective Studies for CT-P13 Switching in IBD

\begin{tabular}{|c|c|c|c|c|c|}
\hline Study & Country & Design & $\begin{array}{l}\text { Sample } \\
\text { size }\end{array}$ & $\begin{array}{l}\text { Follow-up } \\
\text { (wk) }\end{array}$ & Outcome \\
\hline Jørgensen et al. ${ }^{29}$ & Norway & $\begin{array}{l}\text { Randomized, } \\
\text { non-inferiority, } \\
\text { double blind }\end{array}$ & $\begin{array}{l}\text { Total 482, CD 155, } \\
\text { UC 93, Others } 234^{\mathrm{a}}\end{array}$ & 52 & $\begin{array}{l}\text { Disease worsening at wk 52: CT-P13 30\% vs. IFX 26\% } \\
\text { (adjusted treatment difference, 4.4\%; 95\% Cl, 12.7-3.9). }\end{array}$ \\
\hline Kolar et al. ${ }^{31}$ & Czech & Observational & Total 74, CD 56, UC 18 & 56 & Clinical remission: $72.2 \%$ at wk 0 vs. $77.8 \%$ at wk 56 \\
\hline Razanskaite et al. ${ }^{32}$ & UK & Observational & $\begin{array}{l}\text { Total } 143, \text { CD } 118, \\
\text { UC 23, IBDU } 2\end{array}$ & $\begin{array}{l}\text { At least } 3 \text { doses } \\
\text { of CT-P13 }\end{array}$ & $\begin{array}{l}\text { No difference in mean CRP, albumin, and hemoglobin } \\
\text { levels, and platelet and white cell counts } \\
\text { Improvement of mean IBD-control-8 score after switch }\end{array}$ \\
\hline
\end{tabular}

${ }^{a}$ Rheumatologic and dermatologic diseases, including ankylosing spondylitis, rheumatoid arthritis, psoriatic arthritis, and chronic plaque psoriasis. IFX, originator infliximab; IBDU, IBD unspecified. 
enced improvement in perianal disease at week 46 . In addition, there was no increase in immunogenicity in switched patients (antidrug antibody [ADA] positivity $9.5 \%$ at switch vs. $6.0 \%$ at week $54 ; P=0.54$ ). The types and frequency of adverse events were comparable to originator infliximab in both cohorts. During the follow-up, CT-P13 was discontinued in 7 patients with CD due to serious adverse events, including 2 patients from the switching group ( 1 with delayed allergic reaction and 1 with fibrous dysplasia located in maxilla) and 5 patients from the naive group ( 2 patients with skin complications including abscesses and rash, 2 patients experiencing lupus-like joint symptoms, and 1 patient with palmoplantar pustulosis). Razanskaite et al..$^{32}$ reported a switching experience from the United Kingdom where 143 IBD patients were switched from originator infliximab to CT-P13. Patients reported a similar incidence in side effects before and after the switch. There was no significant change in drug persistence between patients treated with CT-P13 in the preceding year and those treated with originator infliximab $(P=0.94)$.

In 2017, recommendations regarding the interchangeability between originals and biosimilars were announced in Europe and the United States. The updated position of the European Crohn's disease and Colitis Organisation (ECCO) on biosimilars stated that the usage of biosimilars is increasing and it plays an important role in the treatment of IBD patients. In addition, the report confirmed that switching from the originals to biosimilars is acceptable ${ }^{33}$ but should be performed after careful discussion among physicians, nurses, pharmacists, and patients. The American Gastroenterological Association has recommended that prescribing physicians should prevent nonmedical switching from originals to biosimilars. ${ }^{34}$

\section{IMMUNOGENICITY AND PHARMACOKINETICS}

Antibodies to biologic agents are known as a risk factor for the development of acute infusion reactions and loss of response, which were reported in $5 \%$ to $23 \%$ of patients treated with originator infliximab. ${ }^{35}$ Patients who developed antibodies against originator infliximab had a 2-fold risk of acute infusion reactions and a 6 -fold risk of serious acute infusion reactions. ${ }^{36}$ The incidence of infusion reactions was $16 \%$ and $21 \%$ in ACCENT 1 and 2 studies (RCTs of originator infliximab in CD), respectively, where the lowest incidence occurred in patients receiving corticosteroids and immunosuppressants. Moreover, in the ACT 1 and 2 studies, infusion reactions were observed in $9.9 \%$ and $11.6 \%$ of patients, respectively. ${ }^{27,37,38}$ In the 2 pivotal trials (PLANETAS and PLANETRA) comparing CT-P13 to originator infliximab in patients with AS and RA, infusion reactions were observed in $3.9 \%$ and $4.9 \%$ of patients with AS, and $6.6 \%$ and $8.3 \%$ of RA patients for CT-P13 and originator infliximab, respectively. ${ }^{18,19}$ A phase III study comparing CT-P13 with originator infliximab in $\mathrm{CD}$ showed no difference in the rate of infusion reactions between both groups at week 30 (CT-P13 $7.2 \%$ vs. originator infliximab $8.3 \%)^{28}$

Bálint et al. ${ }^{39}$ focused on the immunogenicity of CT-P13 in a central European cohort, including 384 consecutive patients (253 CD and 131 UC; 291 Hungarian and 93 Czech) from 13 Hungarian and 1 Czech tertiary IBD sites. Mean CT-P13 trough levels (TLs) were 20.1, 14.7, and $5.0 \mu \mathrm{g} / \mathrm{mL}$ at weeks 2,6 , and 14, respectively, and cumulative rates of ADA positivity were $8.7 \%, 19.3 \%$, and $28.0 \%$ at weeks 0,14 , and 30 , respectively. During induction and maintenance treatment, infusion reactions were observed in $7.3 \%$ of patients (28/384), and were most frequent with the 2nd and 3rd infusions. All infusion reactions were mild to moderate, and the most common symptoms of infusion reactions were flushing, dyspnea, and chest discomfort. CT-P13 therapy had to be terminated in 17 patients, who were switched to adalimumab in 12 cases. The results of this study also suggested comparable rates and characteristics of infusion reactions between CT-P13 and originator infliximab.

In the interim report of a prospective nationwide study published by Gecse et al., ${ }^{40}$ mean TLs of CT-P13 did not differ between CD and UC patients, except for week 6 results, where TLs were significantly higher in CD patients than UC patients $(18.4 \mu \mathrm{g} / \mathrm{mL}$ vs. $6.2 \mu \mathrm{g} / \mathrm{mL} ; P<0.001)$. Patients who had been previously exposed to an anti-TNF agent had lower TLs than naive patients $(15.0 \mu \mathrm{g} / \mathrm{mL}$ vs. $21.5 \mu \mathrm{g} / \mathrm{mL}$ at week $2 ; 7.7 \mu \mathrm{g} /$ $\mathrm{mL}$ vs. $10.2 \mu \mathrm{g} / \mathrm{mL}$ at week 6 ; and $4.8 \mu \mathrm{g} / \mathrm{mL}$ vs. $3.2 \mu \mathrm{g} / \mathrm{mL}$ at week 14, not significant). ADA positivity was detected in $9.1 \%$ and $21.3 \%$ of CD patients and $8.8 \%$ and $23.8 \%$ of UC patients at weeks 0 and 14, respectively. In the same study with an enlarged cohort of 291 patients, ${ }^{41}$ patients with previous originator infliximab exposure had significantly higher ADA positivity in both CD and UC. In this analysis, the overall ADA positivity was $28 \%$ at week $30(24.1 \%$ in naive patients and $44.4 \%$ in previous anti-TNF exposed patients), and concomitant azathioprine (AZA) therapy prevented early ADA formation in antiTNF naive patients in both CD and UC (AZA group 11.2\% vs. non-AZA group $24.6 \%, P=0.012$ ); however, these effects were lost at week 30. In the Norwegian study presented by Jahnsen et al., ${ }^{23}$ which included 78 patients, median TLs at week 14 
were $6.8 \mu \mathrm{g} / \mathrm{mL}$ in $\mathrm{CD}$ and $6.2 \mu \mathrm{g} / \mathrm{mL}$ in UC patients. TLs were not detected in 8 patients ( 4 with CD and 4 with UC), 3 of whom had previously received anti-TNF therapy. Two of the 8 patients had high ADA levels while 5 patients had medium/ high levels. In a multicenter central European study focused on mucosal healing induced by CT-P13 in UC after an induction period, a significant correlation between TLs of CT-P13 and clinical and endoscopic responses was observed, with a cutoff value of $3.15 \mu \mathrm{g} / \mathrm{mL}$ in the ROC analysis for both steroid-free remission and mucosal healing. ${ }^{26}$

Recently, Ben-Horin et al. ${ }^{42}$ examined the presence of crossimmunogenicity of CT-P13 with originator infliximab. This in vitro study revealed that antibodies which had developed against originator infliximab during previous exposure to the drug were also cross-reactive with CT-P13. This important finding suggests that similar immunogenicity and immunodominant epitopes are shared between these infliximab agents (originator infliximab and CT-P13). In a Czech switching cohort of IBD patients treated with CT-P13, no difference in ADA positivity ( $9.5 \%$ vs. $6.0 \%, P=0.54$ ) and an increase in TLs $(3.4 \pm 3.8 \mu \mathrm{g} / \mathrm{mL}$ vs. $4.7 \pm 4.5 \mu \mathrm{g} / \mathrm{mL}, P=0.01)$ were observed at switching and week 56 post-switching from originator infliximab. ${ }^{31}$ In another switching study performed by Smits et al., ${ }^{43,44}$ median TLs obtained during the maintenance phase increased significantly from week 0 to $16(3.5-4.2 \mu \mathrm{g} /$ $\mathrm{mL}, P=0.010$ ), and the proportion of patients with TL within the therapeutic range $(3.0-7.0 \mu \mathrm{g} / \mathrm{mL})$ increased from $39 \%$ (week 0) to 45\% (week 52). Of the 83 patients, 7 (8\%) developed ADA during the follow-up period and 5 had preexisting detectable ADA levels at baseline. No increase in immunogenicity was observed after switching to CT-P13 in pediatric IBD patients in a study by Sieczkowska et al. ${ }^{45}$ who assessed 16 and 15 patients with CD at the time and after switching from originator infliximab to CT-P13, respectively. At switch, 14 out of 16 children had therapeutic TLs and 7 patients had positive ADA levels. After switching, 15 out of 15 patients had therapeutic TLs and only 4 patients developed ADA positivity. Strik et al. ${ }^{46}$ also presented the preliminary results of the SECURE Study which was performed to prospectively evaluate serum drug concentration 16 weeks after switching from originator infliximab to CT-P13 in subjects in stable remission. In 44 CD patients, mean serum TLs were $2.97 \mu \mathrm{g} / \mathrm{mL}$ before switching and $3.25 \mu \mathrm{g} / \mathrm{mL}$ at 16 weeks after switching, thereby demonstrating the non-inferiority of CT-P13 to originator infliximab.

\section{ECONOMIC ISSUES}

The introduction of new, expensive biologic agents is associated with an increase in the direct medical costs of IBD management. Biologic therapy has thus been less accessible in countries with low and middle gross national product (GNP) per capita. Biosimilars could enable health economic savings and improve the access of patients to biologic therapy as they are priced lower than the originals but demonstrate highly comparable efficacy, safety, and immunogenicity profile to their proprietary counterparts. It is predicted that by 2020 , biologic agents will form $28 \%$ of the global pharmaceutical market by value, with biosimilars offering potential savings greater than 50 billion EUR across the European "Big 5" countries and the USA ${ }^{47}$ Cost savings is considered to be the main advantage of biosimilars for IBD patients. By performing web-based surveys regarding biosimilars in 2013 and 2016, the ECCO found that cost saving was thought to be the main advantage of biosimilars by approximately $90 \%$ of respondents. ${ }^{48,49}$ These savings can be reinvested to treat additional patients with IBD or be applied to other segments, including patients and health care professional (e.g., IBD nurses) education. However, the relative price reduction of biosimilars might not be as profound as that of chemical generics, where competition between multiple manufacturers finally drives prices in a downward direction to more than $50 \%$ in most markets. ${ }^{50,51}$ Because of the considerable costs associated with manufacturing, marketing, storage, and special requirements for pharmacovigilance, a greater time might be required to drive the cost savings effect of biosimilars until more biosimilars enter the market to cause a high level of market competition. ${ }^{50}$ Nonetheless, a massive price reduction for biosimilars has been observed in various countries. In Norway, CT-P13 enabled a cost reduction of $51 \%-65 \%$ compared to originator infliximab; in France, the price discount is $45 \%$, and in Japan, the current price of CTP13 is $67 \%$ lower than that of originator infliximab. ${ }^{52}$ Thus, the magnitude of price reduction may be important for switching prescriptions to biosimilars. Kanters et al. ${ }^{53}$ performed a budget impact analysis using a Delphi panel for the adoption of the biosimilar, infliximab, for rheumatologic disorders and IBD in 5 European countries. In this study, savings were expected in all countries for all diseases, when larger price reductions (50\% or more) of the biosimilar infliximab were performed (i.e., physicians would prescribe biosimilars only when price reductions were sufficiently large). Another survey from the United States showed that of 150 physicians, $83 \%$ would 
prescribe biosimilars if they were $25 \%$ cheaper and would only prescribe biosimilars to naive patients instead of patients currently or were previously treated with the original. ${ }^{54}$

Brodszky et al..$^{55}$ presented a very interesting budget impact analysis that focused on 6 lower- and middle-income European countries, with the assumption of a $25 \%$ price reduction. In the first scenario, 8 million EUR in saving was achieved in these countries if only new IBD patients were treated with CTP13 for a 3-year period (i.e., switching was not allowed in this scenario). In the second scenario, where $80 \%$ of IBD patients received CT-P13 (switching was allowed), 16.9 million EUR in savings was achieved. Most importantly, by saving money, 722 to 1,530 additional IBD patients could be treated with CT-P13. Jha et al. ${ }^{56}$ focused on the budget impact analysis model in 5 higher income European countries and assumed price reductions of $10 \%, 20 \%$, and $30 \%$, respectively. The expected cost savings increased from 11.9 million EUR to 35.8 million EUR in CD and 5.1 million EUR to 15.4 million EUR in UC. If these saving budgets were used to treat additional IBD patients, 1,219-4,701 additional patients could be treated in those 5 countries for 1 year. In the Czech Republic, the rapid and robust reduction (30\%-40\%) in the cost of biosimilars has facilitated earlier initiation of biologic therapy in IBD patients on treatment waiting lists, with an additional 1,000 patients receiving treatment in 2014 compared to the previous year. ${ }^{57} \mathrm{In}$ the switching experience from the United Kingdom, where 143 IBD patients switched from originator infliximab to CTP13 according to Razanskaite et al., ${ }^{32}$ drug acquisition costs decreased by $40,000-60,000$ pounds per month following the initiation of the switching program.

Recently, Rencz et al. ${ }^{58}$ published a probabilistic Markov model comparing the cost-effectiveness of treatment sequences with available biologics, including adalimumab, CTP13, originator infliximab, and vedolizumab, for luminal CD in 9 European countries. In addition, they applied the countryspecific unit costs, discount rates, and a third-party payer perspective to the model. Compared to conventional therapy, CTP13 resulted in the most favorable incremental cost utility ratios, which ranged from 34,580 EUR/quality-adjusted life year (QALY) in Hungary to 77,062 EUR/QALY in Sweden. Based on the calculated results, CT-P13 was recommended as a firstline biologic treatment for luminal $\mathrm{CD}$ that is unresponsive to conventional therapy. Baji et al. ${ }^{59}$ reported the cost-effectiveness model of different biologic sequences including originator infliximab, CT-P13, adalimumab, and vedolizumab in 9 European countries for fistulizing CD. CT-P13 was the most cost-effective drug against the standard care across countries, with incremental cost-effectiveness ratios between 34,684 EUR/QALY and 72,551 EUR/QALY. According to this model, the first choice of therapy in fistulizing CD was CT-P13 and when treatment fails, switching to adalimumab and then to vedolizumab provides the meaningful health benefits required, but at an increased cost. ${ }^{59}$

\section{THE PERSPECTIVES OF PHYSICIANS AND PA- TIENTS}

In 2013 and 2016, the ECCO performed 2 surveys with its members to determine their knowledge of and attitude toward biosimilars. ${ }^{48,49}$ The first survey, performed in 2013 (the year CTP13 was approved by the EMA in Europe), showed that physicians had minor confidence in the use of biosimilars. In addition, lower cost was identified to be the major advantage of biosimilars. However, respondents had concerns regarding the extrapolation of data across indications, and the immunogenicity, safety, and interchangeability of biosimilars. Following more extensive use of biosimilars across Europe and the growing body of evidence regarding their biosimilarity to respective originals, a second survey was performed in 2015. This survey also revealed that cost saving was considered to be the main advantage of biosimilars by most respondents (92\%), and immunogenicity was the main concern (69\% of respondents). Furthermore, the biosimilars were considered to be interchangeable with the proprietary products by $44 \%$ of respondents, which increased relative to that found in the 2013 survey (only 6\%). Nonetheless, $90 \%$ disagreed with the automated substitution by dispensing pharmacists, and only $33 \%$ were against extrapolation across indications compared to $76 \%$ in 2013 . The survey also revealed that only $25 \%$ of the respondents did not favor the extrapolation of data across different subtypes of IBD, compared to 53\% in 2013. Such findings suggest an increase in confidence regarding the use of biosimilars, with only $20 \%$ of respondents having little or no confidence in their use, compared to $63 \%$ in 2013.

A survey from Germany revealed that some patients were reluctant to accept a biosimilar prescription. In addition, this reluctancy was particularly identified among patients who were currently receiving the proprietary medicine and were not displaying any clinically-indicated reasons that required a switch to the biosimilar. ${ }^{60}$ The European Federation of Crohn's and Ulcerative Colitis Association carried out a survey to investigate patients' perspectives regarding biosimilars. ${ }^{61} \mathrm{Be}-$ 
tween 2014 and 2015, 1,181 patients responded to the survey, but only $38 \%$ had prior knowledge of biosimilars and only $25 \%$ had no concerns regarding their use. In contrast, $47 \%$ and $40 \%$ of the respondents expressed their concern regarding its safety and efficacy, respectively, while $35 \%$ were concerned that their molecular basis might differ from the brand-name drugs. More than half of the respondents expressed that cost savings should not precede safety and efficacy, and only $31 \%$ were fully confident in biosimilars, even when they were prescribed the biosimilar and provided with an explanation by the treating physician. This survey also revealed that patients wished to be informed and involved in the decision-making process regarding biosimilar dispensing; $66 \%$ preferred to be told which drug they are prescribed (i.e., original or biosimilar), and $21 \%$ rejected the concept of interchangeability if the patient was not aware. Based on these findings, communication between patients and physicians is important during the course of IBD management.

\section{UNRESOLVED ISSUES}

Several biosimilars, besides CT-P13, are currently in preclinical and clinical trials worldwide. ${ }^{62}$ Also, several infliximab biosimilars other than CT-P13 have been approved by FDA or EMA from 2016 to 2019; Renflexis (Samsung Bioepis), Ixifi (Pfizer), and Avsola (Amgen) are approved by FDA. Zessly (Sandoz) and Flixabi (Samsung Bioepis) are approved by EMA. In addition, there are several adalimumab biosimilars approved by FDA or EMA so far; Amjevita (Amgen), Cyltezo (Boehringer Ingelheim), Hyrimoz (Sandoz), Hadlima (Samsung Bioepis), and Abrilada (Pfizer) are approved by FDA. Kromeya (Fresenius Kabi), Idacio (Fresenius Kabi), Hulio (Mylan S.A.S), Hyrimoz (Sandoz), Hefiya (Sandoz), Halimatoz (Sandoz), Imraldi (Samsung Bioepis), and Amgevita (Amgen) are approved by EMA. In fact, they are either ready to enter or have already entered the market, ${ }^{63,64}$ although there has been a lack of data regarding biosimilar experiences in IBD with them except a few published studies. ${ }^{65,66}$ Also, there still remains a lack of scientific and clinical evidence regarding reverse switching, multiple switching, and cross-switching among biosimilars for IBD patients. Furthermore, automated substitution by the dispensing pharmacists would serve as an additional issue in the era of multiple biosimilars for IBD indications. ${ }^{33}$ Therefore, the extended (i.e., an even longer term) safety of biosimilars should be monitored through formal postmarketing observational studies. ${ }^{34}$

\section{CONCLUSION}

Based on the current findings regarding the efficacy and safety of biosimilars in the field of IBD and the decreased reluctance to use biosimilars by patients and physicians, we recognized that a growing desire exists to cut health care costs and use the savings to invest in and assist more patients. Achieving these measures would ultimately enable the creation of a virtuous cycle where future health care costs are decreased. Several prospective studies are currently ongoing and their results could help to confirm the long-term efficacy and safety of biosimilars, and clarify ongoing debates regarding several unresolved or partially resolved issues, such as extrapolations, switching, and the immunogenicity of biosimilars. As the era of biosimilars is presently unavoidable, gaining a better understanding of biosimilars, especially for near future applications, is a crucial requirement in the field of therapeutics.

\section{FINANCIAL SUPPORT}

The authors received no financial support for the research, authorship, and/or publication of this article.

\section{CONFLICT OF INTEREST}

Doctor Loftus EV Jr. has consulted for AbbVie, Allergan, Amgen, Boehringer Ingelheim, Bristol-Myers Squibb, Celgene, Celltrion Healthcare, Eli Lilly, Genentech, Gilead, Janssen, Pfizer, Takeda, and UCB; and has received research support from AbbVie, Amgen, Bristol-Myers Squibb, Celgene, Genentech, Gilead, Janssen, Pfizer, Robarts Clinical Trials, Takeda, and UCB. No other potential conflict of interest relevant to this article was reported.

\section{AUTHOR CONTRIBUTION}

Conceptualization: Park SH, Park JC, Loftus EV Jr. Writing original draft: Park SH, Park JC, Loftus EV Jr. Writing - review and editing: Lukas M, Kolar M. Approval of final manuscript: all authors.

\section{ORCID}

Park SH

https://orcid.org/0000-0002-5366-5749

Park JC

https://orcid.org/0000-0003-0860-3642

Lukas M 
Kolar M

Loftus EV Jr

\section{REFERENCES}

1. Rungoe C, Langholz E, Andersson M, et al. Changes in medical treatment and surgery rates in inflammatory bowel disease: a nationwide cohort study 1979-2011. Gut 2014;63:1607-1616.

2. Park SH, Yang SK, Park SK, et al. Long-term prognosis of Crohn's disease and its temporal change between 1981 and 2012: a hospital-based cohort study from Korea. Inflamm Bowel Dis 2014;20:488-494.

3. Lee HS, Park SH, Yang SK, et al. Long-term prognosis of ulcerative colitis and its temporal change between 1977 and 2013: a hospital-based cohort study from Korea. J Crohns Colitis 2015; 9:147-155.

4. Aniwan S, Park SH, Loftus EV Jr. Epidemiology, natural history, and risk stratification of Crohn's disease. Gastroenterol Clin North Am 2017;46:463-480.

5. Molodecky NA, Soon IS, Rabi DM, et al. Increasing incidence and prevalence of the inflammatory bowel diseases with time, based on systematic review. Gastroenterology 2012;142:4654.

6. Kappelman MD, Rifas-Shiman SL, Porter CQ, et al. Direct health care costs of Crohn's disease and ulcerative colitis in US children and adults. Gastroenterology 2008;135:1907-1913.

7. Kappelman MD, Moore KR, Allen JK, Cook SF. Recent trends in the prevalence of Crohn's disease and ulcerative colitis in a commercially insured US population. Dig Dis Sci 2013;58:519525.

8. Marchetti M, Liberato NL. Biological therapies in Crohn's disease: are they cost-effective? A critical appraisal of modelbased analyses. Expert Rev Pharmacoecon Outcomes Res 2014;14:815-824.

9. Park DI. Current status of biosimilars in the treatment of inflammatory bowel diseases. Intest Res 2016;14:15-20.

10. Declerck P, Mellstedt H, Danese S. Biosimilars: terms of use. Curr Med Res Opin 2015;31:2325-2330.

11. Guidance for industry: quality considerations in demonstrating biosimilarity to a therapeutic protein product to a reference product. US Food and Drug Administration Web site. https:// www.fda.gov/downloads/drugs/guidances/ucm291134.pdf. Accessed Jan 12, 2020.

12. Müller-Ladner U, Hong S, Oh C, Taylor P. Scientific rationale behind the development and approval of biosimilar infliximab (CT-P13) in Europe. Expert Rev Clin Immunol 2015;11
Suppl 1:S5-S14.

13. Schneider CK. Biosimilars in rheumatology: the wind of change. Ann Rheum Dis 2013;72:315-318.

14. Chang S, Hanauer S. Extrapolation and interchangeability of infliximab and adalimumab in inflammatory bowel disease. Curr Treat Options Gastroenterol 2017;15:53-70.

15. McCamish M, Woollett G. The state of the art in the development of biosimilars. Clin Pharmacol Ther 2012;91:405-417.

16. FDA approves Inflectra, a biosimilar to Remicade. US Food and Drug Administration Web site. https://www.fda.gov/ NewsEvents/Newsroom/PressAnnouncements/ucm494227. htm. Updated Apr 5, 2016. Accessed Jan 12, 2020.

17. Beck A, Reichert JM. Approval of the first biosimilar antibodies in Europe: a major landmark for the biopharmaceutical industry. MAbs 2013;5:621-623.

18. Park W, Hrycaj P, Jeka S, et al. A randomised, double-blind, multicentre, parallel-group, prospective study comparing the pharmacokinetics, safety, and efficacy of CT-P13 and innovator infliximab in patients with ankylosing spondylitis: the PLANETAS study. Ann Rheum Dis 2013;72:1605-1612.

19. Yoo DH, Hrycaj P, Miranda P, et al. A randomised, doubleblind, parallel-group study to demonstrate equivalence in efficacy and safety of CT-P13 compared with innovator infliximab when coadministered with methotrexate in patients with active rheumatoid arthritis: the PLANETRA study. Ann Rheum Dis 2013;72:1613-1620.

20. Jung YS, Park DI, Kim YH, et al. Efficacy and safety of CT-P13, a biosimilar of infliximab, in patients with inflammatory bowel disease: a retrospective multicenter study. J Gastroenterol Hepatol 2015;30:1705-1712.

21. Kang YS, Moon HH, Lee SE, Lim YJ, Kang HW. Clinical experience of the use of CT-P13, a biosimilar to infliximab in patients with inflammatory bowel disease: a case series. Dig Dis Sci 2015;60:951-956.

22. Park SH, Kim YH, Lee JH, et al. Post-marketing study of biosimilar infliximab (CT-P13) to evaluate its safety and efficacy in Korea. Expert Rev Gastroenterol Hepatol 2015;9 Suppl 1:3544.

23. Jahnsen J, Detlie TE, Vatn S, Ricanek P. Biosimilar infliximab (CT-P13) in the treatment of inflammatory bowel disease: a Norwegian observational study. Expert Rev Gastroenterol Hepatol 2015;9 Suppl 1:45-52.

24. Gecse KB, Vegh Z, Kurti Z, et al. P331 Final results on efficacy and safety of biosimilar infliximab after one-year: results from a prospective nationwide cohort. J Crohn Colitis 2017;11 (Suppl 1):S246. 
25. Guidi L, Fiorino G, Variola A, et al. OP005 The PROSIT cohort of infliximab biosimilar in IBD: a prolonged follow-up on the efficacy and safety across Italy. J Crohn Colitis 2017;11 (Suppl 1):S3.

26. Farkas K, Rutka M, Golovics PA, et al. Efficacy of infliximab biosimilar CT-P13 induction therapy on mucosal healing in ulcerative colitis. J Crohns Colitis 2016;10:1273-1278.

27. Rutgeerts P, Sandborn WJ, Feagan BG, et al. Infliximab for induction and maintenance therapy for ulcerative colitis. N Engl J Med 2005;353:2462-2476.

28. Ye BD, Pesegova M, Alexeeva O, et al. Efficacy and safety of biosimilar CT-P13 compared with originator infliximab in patients with active Crohn's disease: an international, randomised, double-blind, phase 3 non-inferiority study. Lancet 2019;393:1699-1707.

29. Jørgensen KK, Olsen IC, Goll GL, et al. Switching from originator infliximab to biosimilar CT-P13 compared with maintained treatment with originator infliximab (NOR-SWITCH): a 52-week, randomised, double-blind, non-inferiority trial. Lancet 2017;389:2304-2316.

30. Joergensen KK, Olsen IC, Goll GL, et al. Biosimilar infliximab (CT-P13) is not inferior to originator infliximab: explorative IBD subgroup-analyses in Crohn's disease and ulcerative colitis from the nor-switch trial. Gastroenterology 2017;152(5 Suppl 1):S65-S66.

31. Kolar M, Duricova D, Bortlik M, et al. Infliximab biosimilar (Remsima") in therapy of inflammatory bowel diseases patients: experience from one tertiary inflammatory bowel diseases centre. Dig Dis 2017;35:91-100.

32. Razanskaite V, Bettey M, Downey L, et al. Biosimilar infliximab in inflammatory bowel disease: outcomes of a managed switching programme. J Crohns Colitis 2017;11:690-696.

33. Danese S, Fiorino G, Raine T, et al. ECCO position statement on the use of biosimilars for inflammatory bowel disease: an update. J Crohns Colitis 2017;11:26-34.

34. AGA makes six recommendations to FDA on interchangeable biosimilars. American Gastroenterological Association Web site. http://www.gastro.org/news_items/aga-makes-six-recommendations-to-fda-on-interchangeable-biosimilars. Updated May 25, 2017. Accessed Jan 12, 2020.

35. Lichtenstein L, Ron Y, Kivity S, et al. Infliximab-related infusion reactions: systematic review. J Crohns Colitis 2015;9:806815.

36. O'Meara S, Nanda KS, Moss AC. Antibodies to infliximab and risk of infusion reactions in patients with inflammatory bowel disease: a systematic review and meta-analysis. Inflamm
Bowel Dis 2014;20:1-6.

37. Sands BE, Anderson FH, Bernstein CN, et al. Infliximab maintenance therapy for fistulizing Crohn's disease. N Engl J Med 2004;350:876-885.

38. Hanauer SB, Feagan BG, Lichtenstein GR, et al. Maintenance infliximab for Crohn's disease: the ACCENT I randomised trial. Lancet 2002;359:1541-1549.

39. Bálint A, Rutka M, Végh Z, et al. Frequency and characteristics of infusion reactions during biosimilar infliximab treatment in inflammatory bowel diseases: results from Central European nationwide cohort. Expert Opin Drug Saf 2017;16:885-890.

40. Gecse KB, Lovász BD, Farkas K, et al. Efficacy and safety of the biosimilar infliximab CT-P13 treatment in inflammatory bowel diseases: a prospective, multicentre, nationwide cohort. J Crohns Colitis 2016;10:133-140.

41. Lovasz BD, Kurti Z, Rutka M, et al. DOP033. Immunogenicity profile and predictors of TLs and ADA development of biosimilar infliximab during the first 6 months of the therapy: results from a prospective nationwide cohort. J Crohn Colitis 2016;10(Suppl 1):S46.

42. Ben-Horin S, Yavzori M, Benhar I, et al. Cross-immunogenicity: antibodies to infliximab in Remicade-treated patients with IBD similarly recognise the biosimilar Remsima. Gut 2016;65: 1132-1138.

43. Smits LJ, Derikx LA, de Jong DJ, et al. Clinical outcomes following a switch from Remicade ${ }^{\circledR}$ to the biosimilar CT-P13 in inflammatory bowel disease patients: a prospective observational cohort study. J Crohns Colitis 2016;10:1287-1293.

44. Smits LJT, Grelack A, Derikx LAAP, et al. Long-term clinical outcomes after switching from Remicade $\left({ }^{\mathbb{B}}\right)$ to biosimilar CTP13 in inflammatory bowel disease. Dig Dis Sci 2017;62:31173122.

45. Sieczkowska J, Jarzebicka D, Oracz G, et al. P617. Immunogenicity after switching from reference infliximab to biosimilar in children with Crohn's disease. J Crohn Colitis 2016;10 (Suppl 1):S413-S414.

46. Strik AS, van de Vrie W, Megen Y, et al. Unchanged infliximab serum concentrations after switching from the originator infliximab to the biosimilar CT-P13 in patients with quiescent Crohn's disease: a prospective study. Gastroenterology 2017; 152(5 Suppl 1):S66.

47. Delivering on the potential of biosimilar medicines: the role of functioning competitive markets. IMS Health Web site. https: //www.medicinesforeurope.com/wp-content/uploads/2016/ 03/IMS-Institute-Biosimilar-Report-March-2016-FINAL.pdf. Updated Jun 2016. Accessed Jan 12, 2020. 
48. Danese S, Fiorino G, Michetti P. Viewpoint: knowledge and viewpoints on biosimilar monoclonal antibodies among members of the European Crohn's and Colitis Organization. J Crohns Colitis 2014;8:1548-1550.

49. Danese S, Fiorino G, Michetti P. Changes in biosimilar knowledge among European Crohn's Colitis Organization [ECCO] members: an updated survey. J Crohns Colitis 2016;10:13621365.

50. Dave CV, Kesselheim AS, Fox ER, Qiu P, Hartzema A. High generic drug prices and market competition: a retrospective cohort study. Ann Intern Med 2017;167:145-151.

51. Hirsch BR, Lyman GH. Will biosimilars gain momentum? J Natl Compr Canc Netw 2013;11:1291-1297.

52. Gulacsi L, Pentek M, Rencz F, et al. Biosimilars for the management of inflammatory bowel diseases: economic considerations. Curr Med Chem 2019;26:259-269.

53. Kanters TA, Stevanovic J, Huys I, Vulto AG, Simoens S. Adoption of biosimilar infliximab for rheumatoid arthritis, ankylosing spondylitis, and inflammatory bowel diseases in the EU5: a budget impact analysis using a Delphi panel. Front Pharmacol 2017;8:322.

54. US doctors poised to prescribe biosimilars. GaBI Online -Generics and Biosimilars Initiative Web site. http://www.gabionline.net/Biosimilars/General/US-doctors-poised-to-prescribe-biosimilars. Updated Mar 18, 2016. Accessed Jan 12, 2020.

55. Brodszky V, Rencz F, Péntek M, Baji P, Lakatos PL, Gulácsi L. A budget impact model for biosimilar infliximab in Crohn's disease in Bulgaria, the Czech Republic, Hungary, Poland, Romania, and Slovakia. Expert Rev Pharmacoecon Outcomes Res 2016;16:119-125.

56. Jha A, Upton A, Dunlop WC, Akehurst R. The budget impact of biosimilar infliximab (Remsima $\left.{ }^{\circledR}\right)$ for the treatment of autoimmune diseases in five European countries. Adv Ther 2015;32:
742-756

57. Khraishi M, Stead D, Lukas M, Scotte F, Schmid H. Biosimilars: a multidisciplinary perspective. Clin Ther 2016;38:1238-1249.

58. Rencz F, Gulácsi L, Péntek M, et al. Cost-utility of biological treatment sequences for luminal Crohn's disease in Europe. Expert Rev Pharmacoecon Outcomes Res 2017;17:597-606.

59. Baji P, Gulácsi L, Brodszky V, et al. Cost-effectiveness of biological treatment sequences for fistulising Crohn's disease across Europe. United European Gastroenterol J 2018;6:310321.

60. Sullivan E, Piercy J, Waller J, Black CM, Kachroo S. Assessing gastroenterologist and patient acceptance of biosimilars in ulcerative colitis and Crohn's disease across Germany. PLoS One 2017;12:e0175826.

61. Peyrin-Biroulet L, Lönnfors S, Roblin X, Danese S, Avedano L. Patient perspectives on biosimilars: a survey by the European Federation of Crohn's and Ulcerative Colitis Associations. J Crohns Colitis 2017;11:128-133.

62. Danese S, Bonovas S, Peyrin-Biroulet L. Biosimilars in IBD: from theory to practice. Nat Rev Gastroenterol Hepatol 2017;14:22-31.

63. Biosimilar Product Information. US Food and Drug Administration Web site. https://www.fda.gov. Accessed Jan 12, 2020.

64. Medicines_Search_Biosimilar. European Medicines Agency Web site. https://www.ema.europa.eu. Accessed Jan 12, 2020

65. Macaluso FS, Cappello M, Giuffrida E, et al. Letter: SPOSIB SB2-a Sicilian prospective observational study of IBD patients treated with infliximab biosimilar SB2. Aliment Pharmacol Ther 2019;49:234-236.

66. Goncalves J, Myung G, Park M, Jeong D, Ghil J. SB5 shows crossimmunogenicity to adalimumab but not infliximab: results in patients with inflammatory bowel disease or rheumatoid arthritis. Therap Adv Gastroenterol 2019;12:1756284819891081. 